\title{
A ESTRATÉGIA DE INCORPORAÇÃO DOS CRITÉRIOS DE COMPRAS PÚBLICAS SUSTENTÁVEIS EM UMA UNIVERSIDADE FEDERAL
}

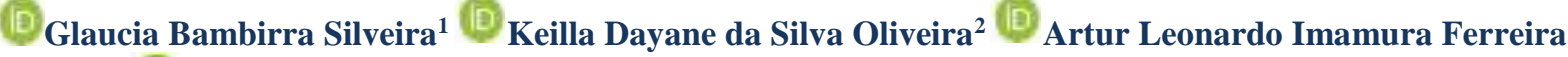 \\ da Silva ${ }^{3}$ (D) Isabel Cristina dos Santos ${ }^{4}$
}

\author{
${ }^{1}$ Doutoranda em Administração pela Universidade Municipal de São Caetano do Sul (USCS). São Caetano do Sul, SP - \\ Brasil. glaucia.bambirra@ufabc.edu.br \\ ${ }^{2}$ Doutoranda em Administração pela Universidade Municipal de São Caetano do Sul (USCS). São Caetano do Sul, SP_- \\ Brasil. keilladsoliveira@gmail.com \\ ${ }^{3}$ Doutorando em Administração pela Universidade Municipal de São Caetano do Sul (USCS). São Caetano do Sul, SP - \\ Brasil.turimamura@yahoo.com.br \\ ${ }^{4}$ Doutora em Engenharia (Produção), docente no Programa de Pós Graduação em Administração - PPGA/USCS. São \\ Caetano do Sul, SP - Brasil. isabel.santos@prof.uscs.edu.br
}

\section{Resumo}

Objetivo: Relatar quais as estratégias e intervenções desenvolvidas na implantação dos critérios de sustentabilidade nas compras públicas realizadas no âmbito da instituição de ensino superior brasileira.

Metodologia: A pesquisa possui abordagem qualitativa do tipo exploratório, com a aplicação da técnica de observação participante e análise documental, ocorridas entre março de 2015 a março de 2020.

Originalidade/Relevância: Esse trabalho contribui para a discussão sobre o processo de implementação das compras públicas sustentáveis e as estratégias utilizadas para maior eficiência.

Resultados: Os principais resultados indicaram que a Universidade Federal do ABC (UFABC) está em fase avançada de implementação dos critérios de compras sustentáveis, que ocorrem de forma institucionalizada e em obediência às normas públicas de aquisições e contratações promulgadas pelo Poder Público Federal, inclusive com a aceitação e o envolvimento dos servidores da universidade.

Contribuições/ implicações: A experiência da UFABC contribui para a disseminação do conhecimento sobre as etapas percorridas por uma instituição de ensino público na implementação dos critérios de sustentabilidade nas compras públicas.

Palavras-chave: Sustentabilidade. Compras públicas sustentáveis. Universidade pública.

\section{THE STRATEGY OF INCORPORATING THE SUSTAINABLE PUBLIC PROCUREMENT CRITERIA AT A FEDERAL UNIVERSITY}

\begin{abstract}
Objective: To report which strategies and interventions were developed in the implementation of sustainability criteria in public purchases carried out within the higher Brazilian education institution.

Methodology: The research has a qualitative and exploratory approach, underlined by the participant observation technique and documentary analysis, regarding the period from March 2015 to March 2020.

Originality/Relevance: This technical report contributes to the discussion on the sustainable public procurement implementation process and the strategies used for reaching better efficiency.

Results: The main results pointed out that Federal University of $A B C$ (UFABC) has been advancing the process of implementing sustainable procurement criteria in all its facilities and following the public
\end{abstract}

standards for acquisitions and contracts, as required by the Federal Government rules, including the acceptance and involvement of university employees.

Contributions/ implications: UFABC's experience contributes to disseminate knowledge on the implementation of sustainability criteria in public procurement process regarding a public higher education institution.

Keywords: Sustainability. Sustainable public procurement. Public university.

\section{LA ESTRATEGIA DE INCORPORAR LOS CRITERIOS DE CONTRATACIÓN PÚBLICA SOSTENIBLE EN UNA UNIVERSIDAD FEDERAL}

\section{Resumen}

Objetivo: Informar qué estrategias e intervenciones se desarrollaron en la aplicación de criterios de sostenibilidad en las compras públicas realizadas dentro de la institución de educación superior brasileña.

Metodología: La investigación tiene un enfoque cualitativo y exploratorio, subrayado por la técnica de observación participante y el análisis documental, con respecto al período de marzo de 2015 a marzo de 2020.

Originalidad/Relevancia: Este informe técnico contribuye al debate sobre el proceso de implementación sostenible de la contratación pública y las estrategias utilizadas para lograr una mejor eficiencia.

Resultados: Los principales resultados señalaron que la universidad federal está avanzada en su proceso de implementación de criterios de contratación sostenible en todas sus instalaciones y siguiendo las normas públicas para adquisiciones y contratos, como exige el Gobierno Federal, inclusa la aceptación e participación de los empleados de la Universidad.

Contribuciones/implicaciones: La experiencia de la Universidad Federal del ABC contribuye a difundir el conocimiento sobre cómo implementar criterios de sostenibilidad en la contratación pública, en lo que se refiere a una institución pública de educación superior.

Palabras clave: Sostenibilidad. Contratación pública sostenible. Universidad pública.

\section{Cite as / Como citar}

American Psychological Association (APA)

Silveira, G. B., Oliveira, K. D. da S., Silva, A. L. I. F., \& Santos, I. C. (2020, Oct./Dec.). A estratégia de incorporação dos critérios de compras públicas sustentáveis em uma universidade federal. Iberoamerican Journal of Strategic Management (IJSM), 19(4), 172-195.

https://doi.org/10.5585/riae.v19i4.17038. 


\section{Introdução}

Nos últimos anos, a poluição ambiental vem causando devastações em escalas mundiais, desafiando países na busca por um desenvolvimento mais sustentável. Nesse contexto, surge o conceito da compra pública sustentável, um processo de aquisição adotado pelos governos com o intuito de incentivar empresas a implementar projetos e manufaturas ambientalmente amigáveis, visando reduzir o impacto ambiental de um determinado produto durante todo o seu ciclo de vida (Liu, Shi, Xue, \& Wang, 2019).

A compra pública sustentável, segundo Uttam e Roos (2015), é a abordagem pela qual as autoridades públicas podem integrar critérios de sustentabilidade em todas as etapas do processo de compra, incentivando, assim, o respeito às questões ambientais e o desenvolvimento de produtos verdes, bem como buscando resultados e soluções que resultem no menor impacto possível sobre o meio.

Portanto, a licitação sustentável consiste num mecanismo utilizado pelo poder público com critérios estabelecidos por meio da elaboração de um termo de referência e edital licitatório que levam em consideração a concepção socioambiental para aquisição de produtos, serviços e obras (Brammer \& Walker, 2011). Com tais critérios em vista, a administração pública avalia a relevância do potencial para conservação do meio ambiente e a relação custo-benefício de um dado produto, no período de médio a longo prazo, diferentemente do que ocorre no caso das compras realizadas analisando-se somente o critério de menor preço (Araújo \& Teixeira, 2018).

Muitos países adotaram planos de ações nacionais para as compras públicas sustentáveis e estabeleceram metas. No entanto, alguns estudos mostram que, na prática, não foram desencadeadas ações mais específicas, para além do estabelecimento dos critérios ambientais (Melissen \& Reinders, 2012). Para que as mudanças aconteçam, de acordo com Weingaertner e Moberg (2014), é necessário engajamento no processo de aprimoramento do entendimento das complexas interconexões entre as atividades de compra e seus impactos, e dos aspectos que ajudam a identificar o que caracteriza a sustentabilidade.

As compras sustentáveis podem influenciar as tendências de produção e de consumo em um país, bem como estimular a inovação e a diversificação no fornecimento de produtos e serviços. Dessa forma, essa possibilidade aumentou o interesse dos formuladores de políticas públicas, desdobrando-se na abordagem de compras públicas sustentáveis, compras públicas verdes e compras públicas de inovação (Trindade, Antunes \& Partidário, 2019).

Segundo Oliveira e Santos (2015), no Brasil, as compras públicas sustentáveis são menos estruturadas do que em outros países, e enfrentam desafios em termos legais, operacionais e culturais. Contudo, como consequência de novas leis ambientais e sistemas de governança, o Brasil vem trabalhando para orientar o setor público em direção à sustentabilidade (Sousa Jabbour, Jabbour, Sarkis \& Govindan, 2014). E há esforços significativos do governo para expandir iniciativas de 
sustentabilidade, como o desenvolvimento do programa Agenda Ambiental na Administração Pública (A3P).

A A3P é um programa do Ministério do Meio Ambiente, elaborado com o intuito de incentivar a adoção de práticas ambientais nos órgãos públicos, além de reunir informações sobre as práticas ambientais existentes, sendo considerado o maior programa de compras sustentáveis do setor público na América Latina (Delmonico et al., 2018).

O poder de compra das instituições públicas é um fator relevante nas contribuições ao desenvolvimento sustentável, ao promover as compras públicas sustentáveis (Trindade et al., 2019). Os contratos públicos podem ser mais ecológicos, ao estimular a criação de novas formas sustentáveis de produtos e serviços (Neto, 2020).

Diante do cenário voltado à adoção de práticas sustentáveis, o debate se estendeu às instituições de ensino superior. As universidades, enquanto agentes formadores e educadores, têm adotado práticas e estratégias em benefício do uso responsável dos recursos naturais, por meio de compromissos em prol da sustentabilidade (Faganello, Santos \& Fonseca Filho, 2015).

Assim, as compras públicas sustentáveis, realizadas no contexto das universidades federais, podem ser consideradas instrumentos estratégicos para melhoria da eficiência e eficácia na administração pública. Tem-se então como questão de pesquisa entender quais as estratégias e intervenções desenvolvidas pela UFABC na implantação dos critérios de sustentabilidade nos processos de compra e aquisição.

Neste relato técnico, são utilizados os termos licitações sustentáveis e compras públicas sustentáveis com o objetivo de mostrar as estratégias e intervenções desenvolvidas na implantação dos critérios de sustentabilidade nas compras públicas realizadas no âmbito da instituição de ensino superior sob análise.

O presente relato técnico encontra-se estruturado em cinco seções, sendo esta introdução a primeira. A segunda seção aborda os principais conceitos acerca das compras públicas e seu caráter sustentável, além das estratégias para efetuar esse tipo de compra. Em seguida, são apresentados os procedimentos metodológicos utilizados no trabalho. A quarta seção é composta pelas análises e discussões dos resultados. Por fim, a última seção traz as considerações finais do estudo.

\section{Referencial teórico}

Esta seção apresenta os conceitos que serão suporte para o embasamento científico, discorrendo sobre compras públicas, seu caráter sustentável e as estratégias utilizadas para a execução dessas compras. 


\subsection{Compra pública e seu caráter sustentável}

Na última década, os contratos públicos sustentáveis tornaram-se um interesse crescente entre os acadêmicos. E o assunto foi debatido em trabalhos de estudo de caso com abordagens teóricas e específicas (Uttam \& Roos, 2015; Brammer \& Walker, 2011; Silva, Betiol, Villac, \& Nonato, 2018; Sönnichsen \& Clement, 2019). Segundo Brammer e Walker (2011), o tema tem sido levado em consideração principalmente pelo setor público, a fim de estimular o mercado privado em direção à sustentabilidade e à criação de conscientização sobre o assunto.

Compras públicas sustentáveis são entendidas como o processo pelo qual as organizações públicas, visando atender às suas necessidades de bens, serviços e obras de construção, avaliam os custos reais de suas aquisições, buscando gerar benefícios não apenas para a administração pública, como também para a sociedade e a economia, minimizando os danos ao meio ambiente (Silva et al., 2018).

O setor público pode obter algumas vantagens na promoção das compras públicas sustentáveis, tais como o uso mais eficiente dos recursos públicos, melhoria da reputação e a promoção da igualdade social (Jiménez, Lópes \& Escobar, 2019).

Compras sustentáveis também podem ser definidas como a busca de objetivos de desenvolvimento sustentável por meio do processo de compras e suprimentos (Walker, Spencer, Miemczyk, \& Johnsen, 2010), ou ainda, na forma de esforços organizacionais para alcançar ou simplesmente melhorar o desempenho das atividades de compra em termos ambientais, sociais e econômicos (Oruezabala \& Rico, 2012).

Segundo o Programa das Nações Unidas para o Meio Ambiente (2017), as compras públicas representam uma média de $12 \%$ do Produto Interno Bruto (PIB) nos países da OCDE e até 30\% do PIB em muitos países em desenvolvimento. Dessa forma, a alavancagem desse poder de compra de bens e serviços mais sustentáveis pode ajudar os mercados na direção da sustentabilidade, reduzir os impactos negativos de uma organização e até produzir benefícios positivos para o meio ambiente e a sociedade. As compras públicas sustentáveis são agora consideradas por muitas organizações como um instrumento importante para ajudar a alcançar os Objetivos de Desenvolvimento Sustentável (UNEP, 2017).

Segundo Betiol (2013), os programas de compras públicas sustentáveis foram desenvolvidos nos países da OCDE, incluindo União Europeia, EUA, Canadá, Austrália, Nova Zelândia e Japão. Já nos países emergentes, é possível identificar o Brasil, a China, a Índia e a África do Sul como nações que têm investido nesse tema, seja por meio de normas rígidas, seja por meio de programas ou práticas de contratação sustentável.

As especificações de aquisição exigem um produto ou serviço com impacto ambiental mínimo ou menor e/ou um resultado social positivo em relação a outro produto/serviço que atenda ao mesmo objetivo. Sendo assim, as compras públicas sustentáveis oferecem aos governos a oportunidade de liderar o desenvolvimento sustentável em um país, utilizando seu poder de compra como incentivo para 
que empreiteiros ou fornecedores passem a adotar práticas sustentáveis (Claro et al., 2013; Uttam \& Roos, 2015).

Segundo Araújo e Teixeira (2018), diversos autores e organizações mundiais criaram critérios para a implementação das compras públicas sustentáveis, além de considerar os processos a eles relativos. De acordo com os autores, é necessária a integração de critérios ambientais, sociais e econômicos em todas as etapas do procedimento licitatório, conforme apresentado na tabela abaixo.

Tabela 1 - Quadro teórico sobre compras públicas sustentáveis

\begin{tabular}{|c|c|}
\hline $\begin{array}{l}\text { Definições e } \\
\text { características de } \\
\text { licitações sustentáveis }\end{array}$ & $\begin{array}{l}\text { - Necessidade real de se efetuar a compra (BRASIL, 2013; ICLEI, 2008); } \\
\text { - Identificação e priorização de produtos mais sustentáveis (BRASIL, 2013); } \\
\text { - Inserção de critérios socioambientais (BIM, 2011; BRASIL, 2013; 2008b; } \\
\text { ICLEI, 2008; UNEP, 2009b); } \\
\text { - Valorização de custos considerando as consequências ambientais, sociais e } \\
\text { econômicas (UNITED KINGDOM, 2006). }\end{array}$ \\
\hline $\begin{array}{l}\text { Especificações técnicas } \\
\text { do produto }\end{array}$ & $\begin{array}{l}\text { - Uso, operação, manutenção, reuso (UNITED KINGDOM, 2006); } \\
\text { - Composição com menos materiais perigosos ou tóxicos (BRASIL, 2013); } \\
\text { - Geração de menos resíduos (Ibidem); } \\
\text { - Vida útil estendida (Ibidem). }\end{array}$ \\
\hline $\begin{array}{l}\text { Especificações de } \\
\text { desempenho }\end{array}$ & $\begin{array}{l}\text { - Avaliação da vida útil do produto (ICLEI, 2008); } \\
\text { - Alternativa de ser reutilizado/reciclado (BRASIL, 2013); } \\
\text { - Logística e distribuição (UNITED KINGDOM, 2006); } \\
\text { - Opções de reciclagem (Ibidem); } \\
\text { - Disposição final (ICLEI, 2008; UNEP, 2009a). }\end{array}$ \\
\hline $\begin{array}{l}\text { Especificações de método } \\
\text { de produção ou prestação }\end{array}$ & $\begin{array}{l}\text { - Condições de trabalho dos produtores (ICLEI, 2008; UNEP 2009b); } \\
\text { - Materiais renováveis (UNITED KINGDOM, 2006); } \\
\text { - Utilização racional dos recursos naturais (BRASIL, 2013; BIM, 2011; ICLEI, } \\
\text { 2008); } \\
\text { - Eficiência e economicidade no uso dos recursos (BIM, 2011); } \\
\text { - Menor consumo de água ou energia em sua produção/uso (BRASIL, 2013). }\end{array}$ \\
\hline
\end{tabular}

Fonte: Araújo e Teixeira (2018, p. 26)

Estudos apontam que as tecnologias ambientais também podem ser adquiridas quando um órgão público solicita resultados e soluções, ou seja, equipamentos, bens e serviços, procedimentos gerenciais que evitam, reduzem, gerenciam e tratam a poluição e o impacto ambiental de um produto, atividade e processo ao longo de todo o seu ciclo de vida. Essas tecnologias melhoram a eficiência e a competitividade da organização e fornecem soluções para o crescimento sustentável dos mercados público e privado (Uttam \& Roos, 2015).

\subsection{Estratégia nas compras públicas sustentáveis}

As compras públicas sustentáveis são uma questão estratégica cuja popularidade vem aumentando nas últimas décadas. No setor privado, as organizações têm lidado com a sustentabilidade de compras e fornecedores, principalmente de forma voluntária (Chiarini, Opoku \& Vagnoni, 2017). Da 
mesma forma, o setor público vem promovendo práticas de compras sustentáveis, seguindo modelos semelhantes, de acordo com as leis e regulamentos das instituições e governos. As compras públicas representam uma parte significativa do PIB nos países mais industrializados (Rainville, 2017; Bernal, São José \& Retolaza, 2019).

A legislação estimula a inclusão de exigências que são socialmente desejadas nos processos de compras públicas, sendo relevantes seis estratégias para a inclusão de critérios de sustentabilidade em licitações: (i) elaboração dos procedimentos, (ii) ferramentas de monitoramento, (iii) informações e treinamento para tomadores de decisão, (iv) conscientização das pessoas, (v) ações de transparência e (vi) uso de tecnologias da informação e comunicação (TICs) (Bernal et al., 2019).

É necessário incorporar estratégias de engajamento para com os contratados, passando de atividades de policiamento e conformidade para atividades colaborativas, por meio de instrumentos que apoiem o envolvimento do contratado. Além disso, o processo deve promover uma melhor comunicação entre as várias partes envolvidas na construção, bem como facilitar um clima colaborativo baseado em comprometimento (Eriksson \& Westerberg, 2011; Jiménez et al., 2019).

Estudos recentes vêm indicando que a implementação das compras públicas sustentáveis pode ser significativamente prejudicada caso os funcionários envolvidos no processo não possuam conhecimento adequado. Sob outra perspectiva, a conscientização dos funcionários em relação às políticas de implementação demonstrou-se um dos fatores principais para melhorar seu desempenho e atuação em processos de compras públicas sustentáveis (McMurray, Islam, Siwar \& Fien, 2014; Jiménez et al., 2019).

A existência de objetivos diferentes exige ou salienta a definição de prioridades, promovendo uma conscientização substancial dos possíveis conflitos entre eles. No entanto, a percepção de prioridades estratégicas e conflitos de metas depende da subjetividade dos agentes envolvidos em cada organização. Modelos organizacionais distintos poderão definir prioridades diferentes em seus objetivos estratégicos de acordo com sua percepção sobre sustentabilidade (Gelderman, Semeijn, \& Bouma, 2015).

Nesse sentido, o treinamento dos servidores ganha relevo, constituindo-se numa importante estratégia na implantação das compras públicas sustentáveis (Jiménez et al., 2019). A transparência das ações e a participação da comunidade acadêmica também são fatores que influenciam o sucesso do processo (Bernal et al., 2019).

A estrutura organizacional de compras públicas varia de uma estrutura muito simples a uma muito complexa, o que poderia ter uma influência no ajuste da estratégia. As principais alternativas organizacionais discutidas na literatura são as organizações de compras centrais ou descentralizadas, enquanto também as organizações de compras em nível estadual ou local são frequentemente mencionadas (Glas, Schaupp \& Essig, 2017).

Metas estratégicas em compras públicas são frequentemente definidas ou aplicadas por meio de regulamentos legais (Brammer \& Walker, 2011). Segundo Erridge e McIlroy (2002), existem três 
conjuntos de objetivos estratégicos relacionados às compras públicas: (i) objetivos regulatórios, (ii) objetivos comerciais e (iii) objetivos socioeconômicos (políticos). A inclusão de metas socioeconômicas, mais precisamente estratégicas, nas políticas e práticas de compras públicas tem sido progressivamente enfatizada nos últimos anos. Os objetivos estratégicos discutidos são benefícios sociais trazidos à tona por meio das compras sustentáveis (Gelderman, Semeijn \& Bouma, 2015).

A conscientização quanto à importância das aquisições sustentáveis e, consequentemente, os efeitos sobre o desenvolvimento sustentável atraem a atenção dos governantes e das instituições de forma a criar ferramentas para implementação de estratégias (Chersan, Dumitri, Gorgan \& Gorgan, 2020).

\section{Procedimentos metodológicos}

A pesquisa propõe analisar a importância da implementação e do acompanhamento das compras sustentáveis para a execução da estratégia institucional de sustentabilidade da UFABC, visando atingir o objetivo de pesquisa, a qual possui abordagem qualitativa do tipo exploratório. Espera-se prover ao pesquisador uma perspectiva mais aprofundada de reflexão e de investigação diante do tema, problema ou realidade que procura pesquisar (Oliveira, 2008; Mattar, 2001).

O estudo é de natureza aplicada, com a utilização do método de estudo de caso que proporciona o conhecimento de vários tipos de fenômenos, inclusive organizacionais. $\mathrm{O}$ estudo de caso possibilita conhecer melhor os processos organizacionais de uma instituição, bem como alguns dos aspectos comportamentais de seus integrantes (Yin, 2015).

O estudo de caso também permite ao pesquisador lidar com uma ampla gama de possibilidades de investigação de um fenômeno, como a coleta de dados por observação direta, observação participante e análise documental (Yin, 2015).

Dessa forma, para relatar o processo de implementação dos critérios de compras sustentáveis na universidade sob análise, a pesquisa foi desenvolvida por meio do levantamento de campo, inicialmente utilizando-se dados secundários, tais como: documentos e resoluções relacionados ao tema; leis e decretos; mensagens em correio eletrônico trocadas entre as diferentes instâncias de gestão; planos operacionais e das atividades de educação permanente junto aos gestores de unidades e equipes. Esses documentos foram obtidos por meio de consultas à página oficial da Fundação Universidade Federal do $\mathrm{ABC}$ na internet e ao Portal de Compras do Governo Federal, também acessível pela rede.

A coleta dos dados foi realizada por meio da técnica de observação participante, e as informações foram coletadas no período de março de 2015 a março de 2020. A observação participante foi efetuada por um dos autores deste estudo que, além de desenvolver as atividades técnicas e administrativas na referida instituição, participou do processo de formalização e implementação das compras sustentáveis, conduzido pela Pró-Reitoria de Administração, Pró-Reitoria de Planejamento e 
Desenvolvimento Institucional, Comissão de elaboração do Plano de Logística Sustentável e Comissão Permanente de Licitações da UFABC.

A referida técnica é uma das maneiras que permite ao pesquisador envolver-se no fenômeno e, assim, desenvolver o grau de relacionamento de confiança necessário para revelar um retrato mais fiel dos bastidores das realidades de sua experiência (Paterson, Bottorff, \& Hewat, 2003). Nesse contexto, foi possível mapear as ações ocorridas durante todo o processo das compras sustentáveis no âmbito da UFABC.

A análise dos dados compreendeu dois estágios: primeiramente, buscou-se examinar todos os documentos produzidos pela UFABC e pelo Portal de Compras do Governo Federal, que institucionalizou, programou e executou as compras governamentais. Num segundo momento, os esforços do estudo foram direcionados à elucidação dos "bastidores", por meio da observação participante do contexto da implementação das compras sustentáveis.

\section{Resultados e discussão}

Nesta seção, será caracterizada a instituição e o problema encontrado, bem como a descrição das soluções implementadas ao longo do processo.

\subsection{Caracterização da organização e do problema analisado}

A Fundação Universidade Federal do ABC (UFABC), fundação pública com personalidade jurídica de direito público, foi instituída pela Lei Federal n. ${ }^{\circ} 11.145$, de 26 de julho de 2005, sendo pertencente à estrutura do Ministério da Educação e Cultura (MEC). Os objetivos da UFABC consistem em ministrar a educação superior, desenvolver pesquisas e promover a extensão universitária, por meio da atuação multicampi na região do Grande ABC, no Estado de São Paulo (Brasil, 2015).

A UFABC possui instalações físicas nas cidades de Santo André e São Bernardo do Campo, onde são ministradas aulas de graduação e pós-graduação. Os setores administrativos da UFABC estão prioritariamente centralizados no campus de Santo André, dentre eles a Reitoria, suas Pró-Reitorias, Assessorias, Ouvidoria, Corregedoria, Procuradoria Federal e Prefeitura Universitária.

Em virtude de a UFABC ter sido constituída como fundação pública, a administração da universidade deve obediência à lei de licitações. Desse modo, erguendo-se a necessidade de celebrar contrato ou adquirir produtos ou serviços, os setores responsáveis do órgão deverão cumprir procedimento licitatório, com ampla divulgação aos interessados, cumprindo as normas estabelecidas em legislação federal, de modo que todos os seus atos sejam submetidos ao controle do Tribunal de Contas da União e possam ser questionados no Poder Judiciário.

A responsabilidade pelas aquisições e contratações da UFABC é da Pró-Reitoria de Administração (ProAd), cuja estrutura se subdivide no Gabinete (GAB) e em duas coordenações, a Coordenação Geral de Suprimentos e Aquisições (CGSA) e a Coordenação Geral de Finanças e 
Contabilidade (CGFC). Por sua vez, a CGSA é composta por quatro divisões: patrimônio, contratos, importação e aquisições e contratações. Enquanto a CGFC é composta por duas divisões: administração financeira e contabilidade e orçamento:

Figura 1 - Composição da ProAd

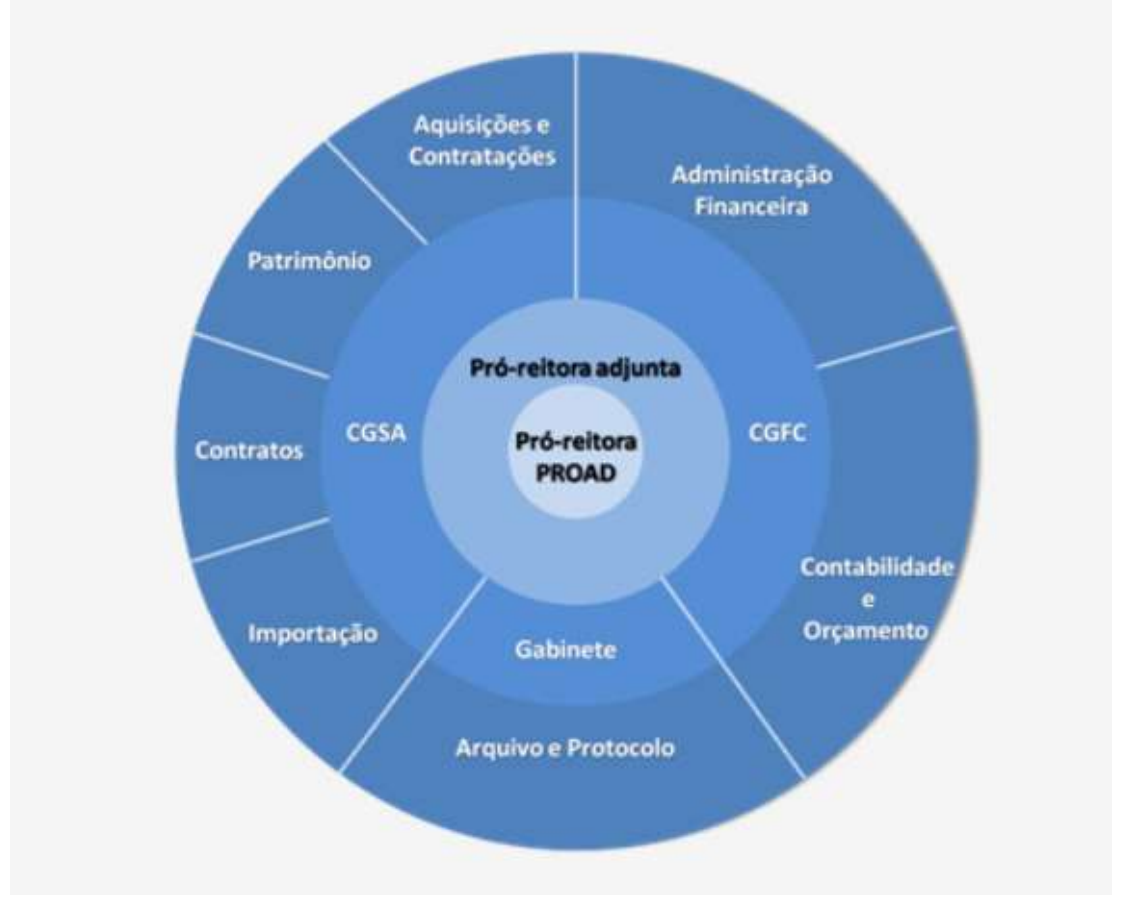

Fonte: ProAd-UFABC (2020).

Seguindo a tendência de centralização do setor de compras visando uma especialização no processo de aquisições (Glas et al., 2017), o único setor responsável pelas aquisições públicas da UFABC é Pró-Reitoria de Administração (ProAd) por meio da Divisão de Aquisições e Contratações (DAC), que é composta por servidores de carreira que são nomeados pregoeiros e fazem parte da Comissão Permanente de Licitação (CPL).

As compras públicas ocorrem por meio de processos administrativos licitatórios, que percorrem um fluxo de etapas previamente estabelecidas e normatizadas por legislação federal, seguindo fielmente os regulamentos legais, que, segundo Brammer e Walter (2011), regem a maioria dos processos de aquisições das instituições públicas.

O processo é iniciado com a avaliação da demanda conforme planejamento prévio da área técnica demandante que inseriu, em momento anterior, a necessidade de compra ou contratação no planejamento de contratações. Em seguida, são realizadas consultas de viabilidade técnica em alguns setores da UFABC, que, dependendo do tipo de produto ou serviço a ser adquirido, podem ser a Divisão de Patrimônio, Divisão de Suprimentos, Divisão de Importação ou Núcleo de Tecnologia da Informação.

Na sequência, o processo é aberto e autuado pelo setor de protocolo, e então são juntados documentos de requisição de compras, planejamento da contratação, consultas e demonstração dos 
valores estimados dos itens em conformidade com as regras licitatórias, e termo de referência preenchido e devidamente assinado pela área técnica demandante da aquisição do produto ou serviço.

Na próxima etapa, o agente de planejamento responsável pela área demandante solicita a liberação dos recursos orçamentários por meio de formulário específico, e encaminha o processo à PróReitoria de Planejamento e Desenvolvimento Institucional (ProPlaDI), que verifica a existência de recursos no sistema governamental. A ProPlaDI então encaminha o processo à CGFC da ProAd para classificação contábil, e, em caso de compra pontual, é feito o pré-empenho do valor estimado pela CGFC. Na etapa seguinte, o processo é encaminhado à Divisão de Contratos da ProAd para prévia análise e, caso necessário, o servidor elabora a minuta de contrato ou de ata de compras, dependendo da natureza da compra pública.

A Divisão de Compras encaminha o processo para a Divisão de Aquisições e Contratações (DAC) da ProAd. Ao receber o processo de compras públicas, o servidor da DAC, que atua também na função de pregoeiro, realiza uma análise prévia dos documentos anexados ao processo, e inicia os procedimentos prévios licitatórios, dentre eles a elaboração do Termo de Referência e Despachos internos. Ao perceber alguma inconsistência ou falta de algum documento imprescindível, o servidor da DAC solicita as correções à área técnica demandante por comunicação eletrônica.

Caso a compra deva ser efetuada pelo Sistema de Registro de Preços (SRP), o servidor da DAC cadastra a ata de registro de preços no sistema ComprasNet (o portal de compras do Governo Federal), procedimento que permite dar ciência aos demais órgãos públicos quanto à intenção de compra, possibilitando, assim, a participação conjunta de outras instituições no mesmo edital. A próxima etapa consiste na elaboração do Termo de Referência com subsequente envio do processo para a análise da Procuradoria Jurídica (PJ) da UFABC. Ao retornar da PJ, o processo é novamente conferido, e o servidor da DAC realiza as correções apontadas, caso sejam de sua alçada, ou encaminha à área técnica demandante para os devidos ajustes.

A fase interna do processo licitatório se finaliza com a publicação do edital de licitação no Diário Oficial da União. A partir daí, a fase externa da licitação é iniciada. Os passos estão ilustrados na figura a seguir. 
Figura 2 - Processo de compras públicas da UFABC antes da adoção das estratégias

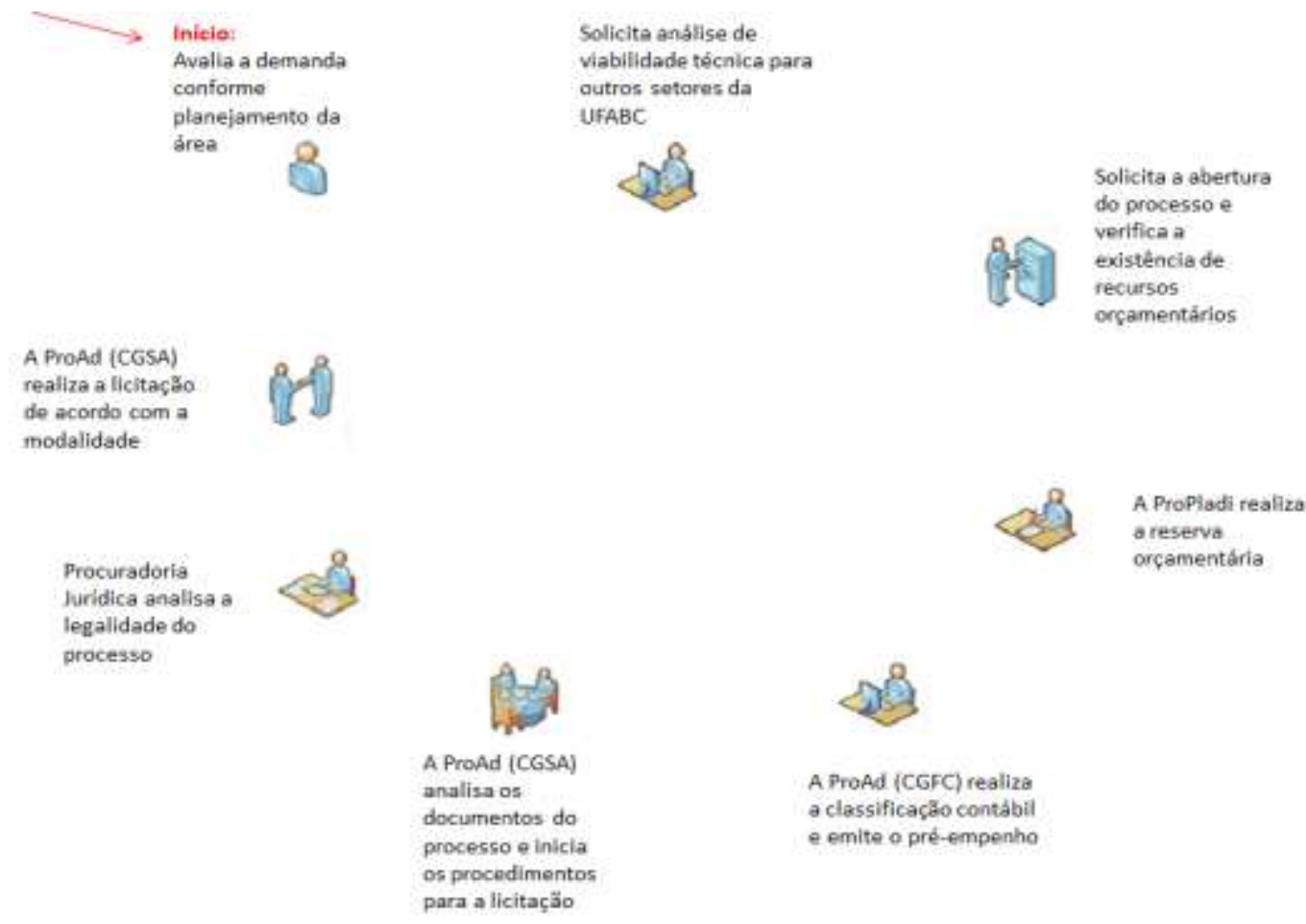

Fonte: Adaptado de ProAd - UFABC (2020).

No processo de compras públicas da UFABC, a comissão gestora instituída pela Reitoria, por meio da Portaria nº 80/2015, para elaboração do Plano de Logística Sustentável (PLS), verificou que, em 2015, poucos eram os termos de referência e editais que apresentavam critérios de sustentabilidade, como exigência de certificados e licenças na fase de habilitação do pregão eletrônico, nas especificações dos objetos a ser licitados e nas cláusulas contratuais.

A comissão apontou que a baixa aplicação dos critérios de sustentabilidade nas compras públicas ocorria por desconhecimento da área técnica demandante acerca dos critérios, e também por conta da falta de definição legal sobre os documentos vinculados à sustentabilidade.

A fragilidade de adoção de critérios de sustentabilidade no processo de compras públicas da UFABC suscitou a iniciativa, por parte da administração da universidade, de elaborar estratégias para instituir regras internas e procedimentos de aquisição aptos a contemplar os requisitos legais que entraram em vigor no decorrer dos anos. Esse esforço foi voltado, de modo especial, à implantação do processo de compras sustentáveis nos moldes de Walker, Spencer, Meimezyk e Johnsen (2010), e também visou estimular fornecedores a alavancar o fornecimento de produtos e serviços sustentáveis (Brammer \& Walter, 2011).

No tocante à legislação produzida para regramento das compras públicas no país, a Tabela 2 traça um amplo panorama. A lei básica que rege os procedimentos licitatórios data do ano de 1993, e foi seguida de outras normativas que complementam as regras básicas, como a regulamentação de 
Silveira, G. B., Oliveira, K. D. da S., Silva, A. L. I. F., \& Santos, I. C. (2020, Oct./Dec.). A estratégia de incorporação dos critérios

pregão eletrônico, elaboração do Plano de Logística Sustentável, regulamentação de compras públicas sustentáveis, etc.

Tabela 2 - Regulação das compras sustentáveis da UFABC e da Administração Pública

\begin{tabular}{|c|c|}
\hline Legislação & Assunto \\
\hline Lei $\mathrm{n}^{\circ} 8.666$, de 21/06/ 1993 & $\begin{array}{l}\text { Principal normativa que rege as licitações, regulamenta o art. } 37 \text {, inciso } \\
\text { XXI da Constituição Federal. }\end{array}$ \\
\hline Decreto $\mathrm{n}^{\mathrm{o}} 2.783$, de $17 / 09 / 1998$ & $\begin{array}{l}\text { Dispõe sobre proibição de aquisição de produtos ou equipamentos que } \\
\text { contenham ou façam uso das Substâncias que Destroem a Camada de } \\
\text { Ozônio - SDO. }\end{array}$ \\
\hline Lei n ${ }^{\circ} 10.520$, de 17/07/2002 & $\begin{array}{l}\text { Institui, nos termos do art. 37, inciso XXI, da Constituição } \\
\text { Federal, modalidade de licitação denominada pregão, para aquisição de } \\
\text { bens e serviços comuns, e dá outras providências. }\end{array}$ \\
\hline Decreto $n^{\circ} 5.940$, de $25 / 10 / 2006$ & $\begin{array}{l}\text { Institui a separação dos resíduos recicláveis descartados pelos órgãos e } \\
\text { entidades da Administração Pública Federal direta e indireta, na fonte } \\
\text { geradora, e a sua destinação às associações e cooperativas dos catadores } \\
\text { de materiais recicláveis, e dá outras providências. }\end{array}$ \\
\hline Lei $\mathrm{n}^{\circ} 12.187$, de 29/12/2009 & $\begin{array}{l}\text { Prevê critérios de preferência nas licitações públicas para propostas que } \\
\text { propiciem maior economia de energia, água e outros recursos naturais. }\end{array}$ \\
\hline Lei n ${ }^{\circ} 12.232$, de 29/04/2010 & $\begin{array}{l}\text { Dispõe sobre as normas gerais para licitação e contratação pela } \\
\text { administração pública de serviços de publicidade prestados por intermédio } \\
\text { de agências de propaganda e dá outras providências. }\end{array}$ \\
\hline Lei n ${ }^{\circ} 12.305$, de 02/08/2010 & $\begin{array}{l}\text { Institui a Política Nacional de Resíduos Sólidos. Tem dentre os objetivos } \\
\text { a prioridade, nas aquisições e contratações governamentais, para produtos } \\
\text { reciclados e recicláveis e para bens, serviços e obras que considerem } \\
\text { critérios compatíveis com padrões de consumo social e ambientalmente } \\
\text { sustentáveis. Estabelece a Logística Reversa. }\end{array}$ \\
\hline Decreto $n^{\circ} 7.404$, de 23/12/2010 & $\begin{array}{l}\text { Estabelece normas para execução da Política Nacional de Resíduos } \\
\text { Sólidos e instituiu o Comitê Interministerial da Política Nacional de } \\
\text { Resíduos Sólidos. }\end{array}$ \\
\hline $\begin{array}{l}\text { Portaria SLTI/MPOG n } 02 / 2010 \text {, } \\
\text { de } 16 / 03 / 2010\end{array}$ & $\begin{array}{l}\text { Regulamenta a compra de tecnologia da informação com critérios } \\
\text { ambientais de sustentabilidade. }\end{array}$ \\
\hline $\begin{array}{l}\text { Instrução Normativa SLTI/MPOG } \\
n^{\circ} 1 \text {, de } 19 / 01 / 2010\end{array}$ & $\begin{array}{l}\text { Dispõe sobre os critérios de sustentabilidade ambiental na aquisição de } \\
\text { bens, contratação de serviços ou obras pela Administração Pública Federal } \\
\text { direta, autárquica e fundacional e dá outras providências. }\end{array}$ \\
\hline $\begin{array}{l}\text { Decreto } \mathrm{n}^{\mathrm{o}} 7.746 \text {, de } 05 / 06 / 2012 \\
\text { alterado pelo Decreto } \mathrm{n}^{\circ} 9.178 / 17\end{array}$ & $\begin{array}{l}\text { Regulamenta o art. } 3^{\circ} \text { da Lei } N^{\circ} 8.666 / 1993 \text {, para estabelecer critérios, } \\
\text { práticas e diretrizes gerais para a promoção do desenvolvimento nacional } \\
\text { sustentável por meio das contratações realizadas pela administração } \\
\text { pública e institui a Comissão Interministerial de Sustentabilidade na } \\
\text { Administração Pública (CISAP). }\end{array}$ \\
\hline $\begin{array}{l}\text { Instrução Normativa SLTI/MPOG } \\
\mathrm{n}^{\circ} 10, \text { de } 12 / 11 / 2012\end{array}$ & $\begin{array}{l}\text { Estabelece regras para elaboração dos Planos de Gestão de Logística } \\
\text { Sustentável. }\end{array}$ \\
\hline Instrução Normativa SEGES/MP & Dispõe sobre as regras e diretrizes do procedimento de contratação de \\
\hline
\end{tabular}




\begin{tabular}{|c|c|}
\hline $\mathrm{N}^{\circ} 05$, de $2605 / 2017$ & $\begin{array}{l}\text { serviços sob o regime de execução indireta no âmbito da Administração } \\
\text { Pública federal direta, autárquica e fundacional. Nas diretrizes para } \\
\text { elaboração dos estudos preliminares, incluir, se possível, critérios e } \\
\text { práticas de sustentabilidade que devem ser veiculados como especificação } \\
\text { técnica do objeto ou como obrigação da contratada. }\end{array}$ \\
\hline $\begin{array}{l}\text { Instrução Normativa SLTI n }{ }^{\circ} .02 \text {, } \\
\text { de } 04 / 06 / 2014\end{array}$ & $\begin{array}{l}\text { Dispõe sobre regras para a aquisição ou locação de máquinas e aparelhos } \\
\text { consumidores de energia pela Administração Pública, e uso da Etiqueta } \\
\text { Nacional de Conservação de Energia (ENCE) nos projetos e respectivas } \\
\text { edificações públicas federais novas ou que recebam retrofit. }\end{array}$ \\
\hline $\begin{array}{l}\text { Instrução Normativa SLTI } n^{\circ} 05 \text {, } \\
\text { de } 27 / 06 / 2014 \text {, alterada pela } \\
\text { IN SEGES } n^{\circ} .03 / 17\end{array}$ & $\begin{array}{l}\text { Dispõe sobre os procedimentos administrativos básicos para a realização } \\
\text { de pesquisa de preços para a aquisição de bens e contratação de serviços } \\
\text { em geral. }\end{array}$ \\
\hline $\begin{array}{l}\text { Portaria da UFABC } n^{\circ} 80, \text { de } \\
06 / 02 / 2015\end{array}$ & $\begin{array}{l}\text { Institui a Comissão Gestora do Plano de Gestão de Logística Sustentável } \\
\text { (PLS) e nomeia servidores para a sua composição. }\end{array}$ \\
\hline $\begin{array}{l}\text { Portaria da UFABC } \mathrm{n}^{\circ} 246, \text { de } \\
06 / 07 / 2016\end{array}$ & $\begin{array}{l}\text { Aprova o Plano de Logística Sustentável da UFABC e nomeia a Comissão } \\
\text { Consultiva à Sustentabilidade da UFABC. }\end{array}$ \\
\hline Decreto $^{\circ}$ 9.177, de 23/10/2017 & $\begin{array}{l}\text { Estabelece normas para assegurar a isonomia na fiscalização e no } \\
\text { cumprimento das obrigações imputadas aos fabricantes, aos importadores, } \\
\text { aos distribuidores e aos comerciantes de produtos, seus resíduos e suas } \\
\text { embalagens sujeitos à logística reversa obrigatória. }\end{array}$ \\
\hline $\begin{array}{l}\text { Instrução Normativa SEGES/MP } \\
\mathrm{n}^{\circ} 05 \text {, de 26/05/2017 }\end{array}$ & $\begin{array}{l}\text { Dispõe sobre as regras e diretrizes do procedimento de contratação de } \\
\text { serviços para elaboração dos estudos preliminares, incluir, se } \\
\text { possível, critérios e práticas de sustentabilidade que devem ser veiculados } \\
\text { como especificação técnica do objeto ou como obrigação da contratada. }\end{array}$ \\
\hline Decreto $^{\circ} 9.373$, de $11 / 05 / 2018$ & $\begin{array}{l}\text { Dispõe sobre a alienação, a cessão, a transferência, a destinação e a } \\
\text { disposição final ambientalmente adequadas de bens móveis no âmbito da } \\
\text { administração pública federal direta, autárquica e fundacional. }\end{array}$ \\
\hline Decreto $n^{\circ} 10.024$, de 20/09/2019 & $\begin{array}{l}\text { Regulamenta a licitação, na modalidade pregão, na forma eletrônica, que } \\
\text { é condicionado aos princípios da legalidade, da impessoalidade, da } \\
\text { moralidade, da igualdade, da publicidade, da eficiência, da probidade } \\
\text { administrativa, do desenvolvimento sustentável, da vinculação ao } \\
\text { instrumento convocatório, do julgamento objetivo, da razoabilidade, da } \\
\text { competitividade, da proporcionalidade e aos que lhes são correlatos. }\end{array}$ \\
\hline
\end{tabular}

Fonte: Elaborado pelos autores (2020).

A UFABC, na qualidade de instituição pública, deve obediência à legislação brasileira, em especial no tocante às compras públicas, reforçando a importância da legislação na adoção dos critérios sustentáveis nas licitações (Bernal et al., 2019). Com a progressiva exigência de inclusão dos critérios de sustentabilidade nas compras públicas ao longo dos anos, em especial após a necessidade de implantação do Plano de Logística Sustentável (PLS), a UFABC iniciou, a partir de fevereiro de 2015, a adoção de estratégias para incorporação dos critérios de sustentabilidade nas compras públicas que realiza. 


\subsection{Incorporação dos critérios de sustentabilidade nas compras da UFABC}

As constantes mudanças na legislação de compras públicas, em especial em relação aos critérios de sustentabilidade, forçam as instituições públicas a promover alterações em seus processos de compras públicas com a mesma frequência em que as normas públicas mudam ou são atualizadas. Isso tende a gerar um trabalho de análise e reelaboração de documentos públicos, a fim de que incluam critérios de sustentabilidade, bem como um aumento da frequência de divulgação e consequente assessoria da DACCGSA-ProAd às áreas técnicas demandantes da UFABC que solicitam as aquisições de produtos e serviços.

O Governo Federal, por meio do Decreto $\mathrm{n}^{\mathrm{o}}$ 7.746, de 6 de junho de 2012, determinou que os órgãos da Administração Pública Federal elaborassem os seus Planos de Gestão de Logística Sustentável (PLS). Em seguida, a Secretaria de Logística e Tecnologia da Informação do Ministério do Planejamento, Orçamento e Gestão (SLTI-MPOG) publicou a Instrução Normativa no 10, de 12 de novembro de 2012, que estabelece regras para a elaboração do PLS.

A situação criou uma insatisfação inicial da parte dos demandantes de compras públicas, pois, com a publicação das novas normativas, fez-se necessário alterar o modus operandi dos processos de aquisições. No contexto da instituição, pôde-se verificar que os colaboradores manifestaram desconforto com a mudança, a qual certamente exigiria o desenvolvimento de novos conhecimentos ou aprimoramento de suas competências.

Houve uma desconfiança inicial da parte dos servidores quanto à eficácia das estratégias da UFABC no tocante à orientação e treinamento dos interessados. Também houve incerteza quanto à necessidade de realização de novos procedimentos, bem como em relação à duração do processo para as novas aquisições.

Dentre os desafios enfrentados pela Pró-Reitoria de Administração, destacaram-se fatores como a escassez de tempo hábil para implementação das mudanças nos procedimentos internos e a pequena quantidade de servidores especializados em compras públicas para absorver as mudanças e repassá-las aos demais servidores da instituição. Diante disso, foi formada uma comissão para a elaboração do PLS da UFABC.

Em 6 de fevereiro de 2015, a UFABC publicou a Portaria $n^{\circ}$ 80, que instituiu comissão gestora composta de servidores responsáveis pela elaboração do PLS da instituição. A comissão nomeada realizou levantamento com membros da comunidade universitária e propôs a formação de sete grupos de trabalho, ficando cada um deles responsável por objetivos específicos previamente definidos e sintetizados em temas.

O grupo de trabalho no 3 (GT3) foi responsável pelo tema "material de consumo e licitações sustentáveis", cujos membros realizaram reuniões periódicas ao longo de dois meses e meio, contando com a participação de discentes, docentes e técnicos-administrativos para diagnóstico das ações já existentes na universidade. Cabe destacar que os trabalhos do grupo deflagram a importância, conforme 
ressaltam Weingaertner e Moberg (2014), do engajamento dos servidores de uma instituição no processo de entendimento das alterações nas atividades de compra.

O GT3 tinha dois objetivos: (i) analisar a dinâmica de uso dos materiais de consumo, abrangendo, no mínimo, papel de impressão, copos descartáveis e cartuchos de impressão; e (ii) selecionar um grupo de editais de licitação (compras e serviços) para verificação da possibilidade de inserção de atributos e cláusulas de sustentabilidade. Os membros do grupo optaram por monitorar os materiais que a Instrução Normativa $n^{\circ}$ 10/2012 estabeleceu em seu Art. $8^{\circ}$, inciso I, quais sejam: papel de impressão, copos descartáveis e cartuchos de impressão. Essa escolha estratégica do grupo deveu-se ao fato de que, devido à amplitude da gama de materiais que a UFABC adquire regularmente, incluindo desde insumos de laboratórios a materiais de cabeamento, o monitoramento de apenas alguns itens facilitaria o processo de análise da equipe.

O GT3 concluiu que a UFABC já realiza o processo de reciclagem de papel, porém, no entendimento do grupo, seria necessária a diminuição da quantidade utilizada e, para isso, foram recomendadas ações como o estabelecimento de cotas de impressão por servidor, utilização de sistemas de informática (SIG) e instalação de ilhas de impressão compartilhadas, medidas essas que já se encontram implementadas na universidade.

Em relação à aquisição de cartuchos de impressão e toner, desde 2011, os termos de referência elaborados pelo Núcleo de Tecnologia da Informação (NTI), bem como os editais de licitação elaborados pela ProAd, já determinam que a contratada recolha os suprimentos de informática utilizados e os encaminhe para reciclagem (UFABC, 2015).

Outra etapa implementada, visando ampliar a participação da comunidade acadêmica na elaboração do PLS, foi a realização do I Fórum de Sustentabilidade da UFABC, que ocorreu em 30 de março de 2015, e teve como principal foco a coleta de informações e a abertura de espaço para as contribuições da comunidade. Na sequência, foram encaminhados questionários por comunicação eletrônica aos servidores e dirigentes da UFABC, com o intuito de realizar um levantamento das ações de sustentabilidade em andamento na instituição, as quais foram relacionadas no PLS ao final do processo.

O PLS foi elaborado e colocado em consulta pública no site da UFABC. As sugestões recebidas foram compiladas e a versão final do documento foi elaborada e aprovada pela Reitoria da UFABC no teor da Portaria $\mathrm{n}^{\circ}$ 246, de 6 de julho de 2016. Houve a divulgação no site da instituição, e versões impressas foram distribuídas aos servidores.

A necessidade de conscientização quanto à importância das compras sustentáveis e a relevância dos efeitos desse tipo de ação para o desenvolvimento sustentável demanda do poder público a criação de ferramentas para implementação de processos de compra que realmente incorporem critérios de sustentabilidade (Chersan et al., 2020), e, nesse sentido, a UFABC tem apresentado um avanço significativo. 
Diversas mudanças ocorreram, em especial após 2016, em relação aos critérios de sustentabilidade em processos de compras públicas, com a promulgação de novas normas legais ao longo dos anos. Os servidores da ProAd são os responsáveis pelas adaptações e criações dos documentos internos relacionados ao processo de compras públicas. Essa pró-reitoria também é responsável pela elaboração dos modelos de documentos necessários à instrução dos processos, como requisições de compra ou contratação e termos de referência por modalidade de aquisição. Esses e outros modelos de documentação estão disponibilizados na página da ProAd da UFABC e são regularmente atualizados (Figura 3).

Figura 3 - Página da web da ProAd com os modelos dos documentos

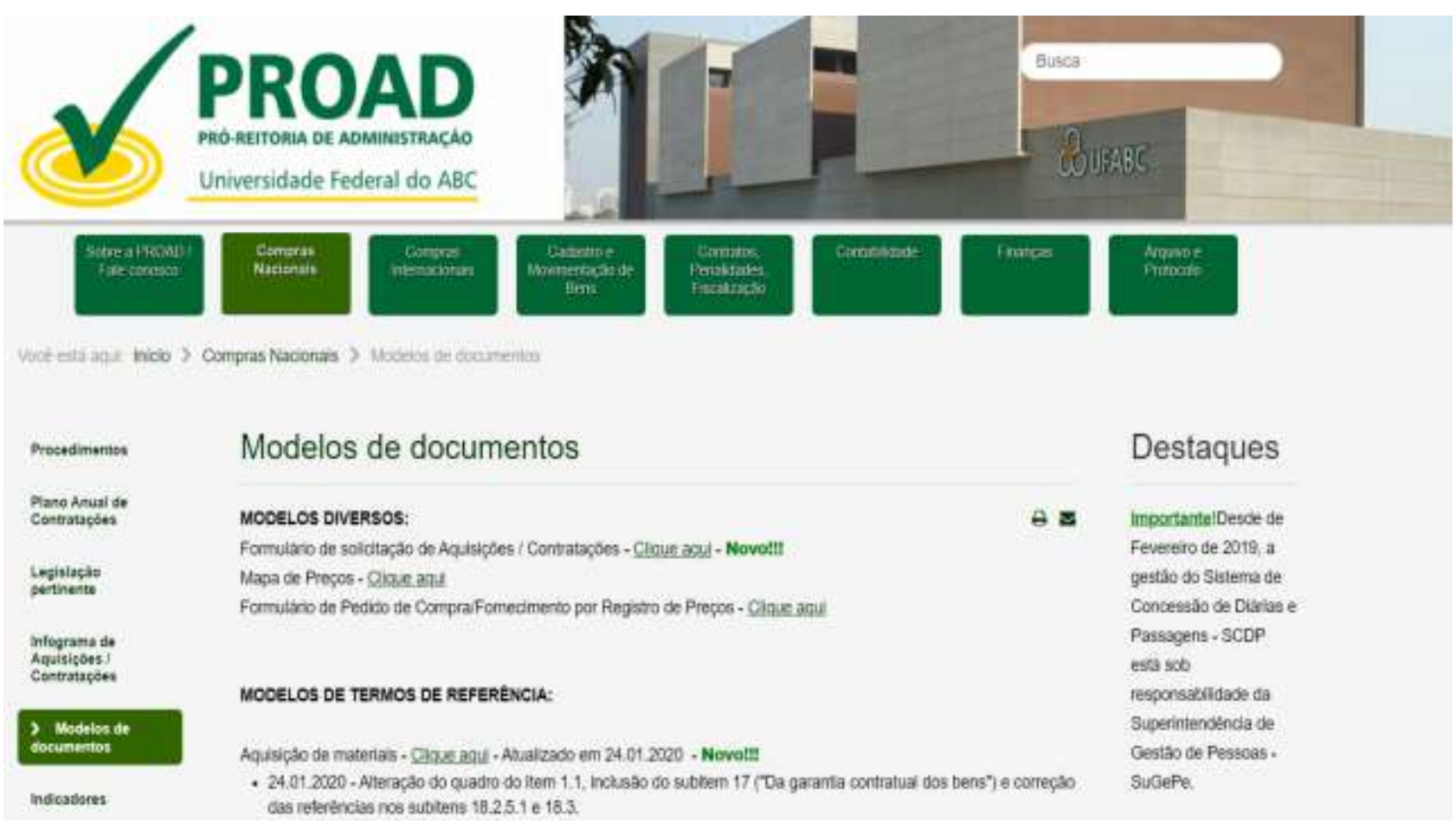

Fonte: ProAd - UFABC (2020)

Com a alteração realizada no texto do Decreto $n^{\circ} 7.746$, de 5 de junho de 2012, pelo Decreto ${ }^{\circ}$ 9.178, de 2017, e com a aprovação da Instrução Normativa $n^{\circ}$ 05, de 26 de maio de 2017, que estabelece as regras e diretrizes do procedimento de contratação de serviços no âmbito da Administração Pública Federal, houve mudanças substanciais em relação aos critérios de sustentabilidade nas contratações públicas, uma vez que o novo teor do referido decreto prevê que a administração pública deverá obedecer aos critérios e práticas de sustentabilidade constantes no Art. $1^{\circ}$, inciso II da IN n ${ }^{\circ}$ 05/2017.

O Decreto $\mathrm{n}^{\circ} 10.024$, de 20 de setembro de 2019, prevê, em seu Art. $2^{\circ}$, dentre os princípios que regem o processo licitatório, o princípio do desenvolvimento sustentável, que deve ser observado em todas as etapas do processo de contratação, em suas "dimensões econômica, social, ambiental e cultural, no mínimo, com base nos planos de gestão de logística sustentável dos órgãos e das entidades” (Brasil, 2019). 
A UFABC, por meio da Divisão de Aquisições e Contratações (DAC-ProAd), atenta às mudanças legislativas, estabeleceu um checklist para aquisições e contratações nacionais, o qual estabelece o passo a passo a ser seguido pela área técnica demandante ao instruir um processo de compra ou contratação, conforme apresentado na Tabela 3. Em seu item 5, o checklist informa como proceder em relação aos critérios e práticas de sustentabilidade, conforme apresentado na tabela abaixo.

Tabela 3 - Checklist de procedimentos para formalizar o processo de compras

\begin{tabular}{|c|c|}
\hline 1 & Analisar a real necessidade da demanda, considerando o planejamento da área. \\
\hline 2 & Identificar se o item se enquadra como despesas de uso comum, conforme Portaria REIT n ${ }^{\circ} 163 / 2017$. \\
\hline 3 & $\begin{array}{l}\text { Caso se trate de despesa de uso comum, enviar e-mail à área responsável indicada na Portaria, a fim de } \\
\text { consultar a disponibilidade do item na UFABC. No caso de bem patrimonial, enviar consulta para a Divisão } \\
\text { de Patrimônio/CGSA/ProAd. }\end{array}$ \\
\hline 4 & $\begin{array}{l}\text { Caso não haja disponibilidade, consultar Ata de Sistema de Registro de Preços (SRP) vigente da UFABC } \\
\text { para atender a demanda. }\end{array}$ \\
\hline & $\begin{array}{l}\text { Não havendo disponibilidade nem Ata de SRP vigente, estabelecer sua demanda considerando } \\
\text { produtos/serviços com critérios e práticas de sustentabilidade: maior vida útil e menor custo de manutenção } \\
\text { do bem e da obra; características de qualidade, durabilidade e segurança; uso racional de recursos naturais } \\
\text { (água, energia, matéria-prima, etc.), destinação de resíduos e logística reversa, reaproveitamento e } \\
\text { reciclagem: }\end{array}$ \\
\hline 5 & $\begin{array}{l}\text { 5.1. Consultar o Guia Nacional de Licitações Sustentáveis da Advocacia-Geral da União como referência } \\
\text { principal para elaboração do TR, considerando: legislação, principais determinações, providências a serem } \\
\text { tomadas e precauções. } \\
\text { 5.2. Consultar o CatMat, selecionando a opção Item Sustentável: "sim". } \\
\text { 5.2.1. Caso não haja item sustentável cadastrado, utilize o código com descrição geral e insira as } \\
\text { características de sustentabilidade no campo "especificação" do TR. } \\
\text { 5.3. No caso de bem patrimonial, consultar a Prefeitura Universitária para verificar a viabilidade técnica de } \\
\text { instalação. }\end{array}$ \\
\hline 6 & Solicitar a abertura do Processo via SIPAC: <https://sig.ufabc.edu.br/sipac/>. \\
\hline 7 & Juntar os documentos ao Processo Administrativo. \\
\hline
\end{tabular}
Fonte: ProAd-UFABC (2020)

Os modelos dos documentos licitatórios elaborados pela Pró-Reitoria de Administração são atualizados pela alta direção da área e primeiramente submetidos à análise da Procuradoria Jurídica da UFABC para validação, para somente depois serem disponibilizados na página da ProAd. As áreas técnicas demandantes são informadas sobre eventuais alterações e recebem a recomendação, via comunicados eletrônicos, para que passem a utilizar os novos modelos. Esse cuidado com a ampla divulgação de dados relevantes para a instrução dos processos de compra está em consonância com as estratégias de propagação de informações e de transparência apontadas por Bernal et al. (2019).

Os servidores da DAC periodicamente realizam reuniões presenciais ou remotas para que sejam transmitidas todas as instruções de como os servidores devem analisar os processos em função das novas normas e novos modelos de documentos. Um dos pontos mais destacados nas reuniões é a necessidade 
de atendimento ao princípio do desenvolvimento sustentável que deve estar presente em todas as etapas do processo de compras públicas.

Importante frisar que, devido à equipe da DAC ser composta por oito servidores que trabalham no mesmo local físico da instituição, as comunicações ocorrem com frequência durante a jornada de trabalho, facilitando a troca de informações e esclarecimentos. A comunicação eletrônica é utilizada entre a equipe e seus superiores, havendo inclusive um endereço de e-mail específico para a Comissão Permanente de Licitações (CPL), no qual são centralizadas todas as comunicações entre a equipe da DAC e os demais setores da UFABC.

O meio eletrônico de comunicação é o preferencial, especialmente pela simplicidade e rapidez na troca de informações, bem como por evitar a circulação desnecessária de pessoas ou documentos, propiciando maior celeridade ao processo de aquisição.

A UFABC estimula os servidores a participar de cursos oferecidos pela Escola Nacional de Administração Pública (ENAP), e de outros cursos voltados à área de atuação, ocorrendo também a contratação de cursos in company. Os servidores da DAC participam de vários cursos e palestras voltados à área de compras públicas, em especial com assuntos sobre as atualizações legislativas. A ENAP, vinculada ao Ministério da Economia, disponibiliza cursos presenciais e a distância, constituindo-se num relevante canal para obtenção de conhecimento.

O processo para a realização de pregão eletrônico requer que o material ou serviço a ser adquirido ou contratado corresponda a um bem ou serviço comum. Não sendo esse o caso, o pregoeiro deverá optar por outra modalidade, dependendo dos critérios impostos pela Lei de Licitações ( ${ }^{\circ} 8.666$ de 1993). Quanto aos critérios de sustentabilidade, a área técnica demandante deverá consultar o Guia Nacional de Licitações Sustentáveis da Advocacia Geral da União (2016), o qual orienta quanto à adoção desses critérios nas compras públicas, e quanto aos modos de aplicar os requisitos de sustentabilidade ao processo de compras ou de justificar a sua não adoção no caso concreto.

Na etapa final, o demandante solicitará a abertura de processo no Sistema Integrado de Patrimônio, Administração e Contratos (SIPAC), no qual são centralizadas informações acadêmicas e administrativas, bem como dados referentes a recursos humanos, planejamento, processos eleitorais, comunicação e gestão de eventos. O acesso se dá por inserção de credenciais (login e senha) estabelecidas previamente pelo servidor. A tela inicial para acesso ao SIPAC é exibida na figura a seguir. 
Figura 4 - Imagem da tela de acesso inicial do SIPAC

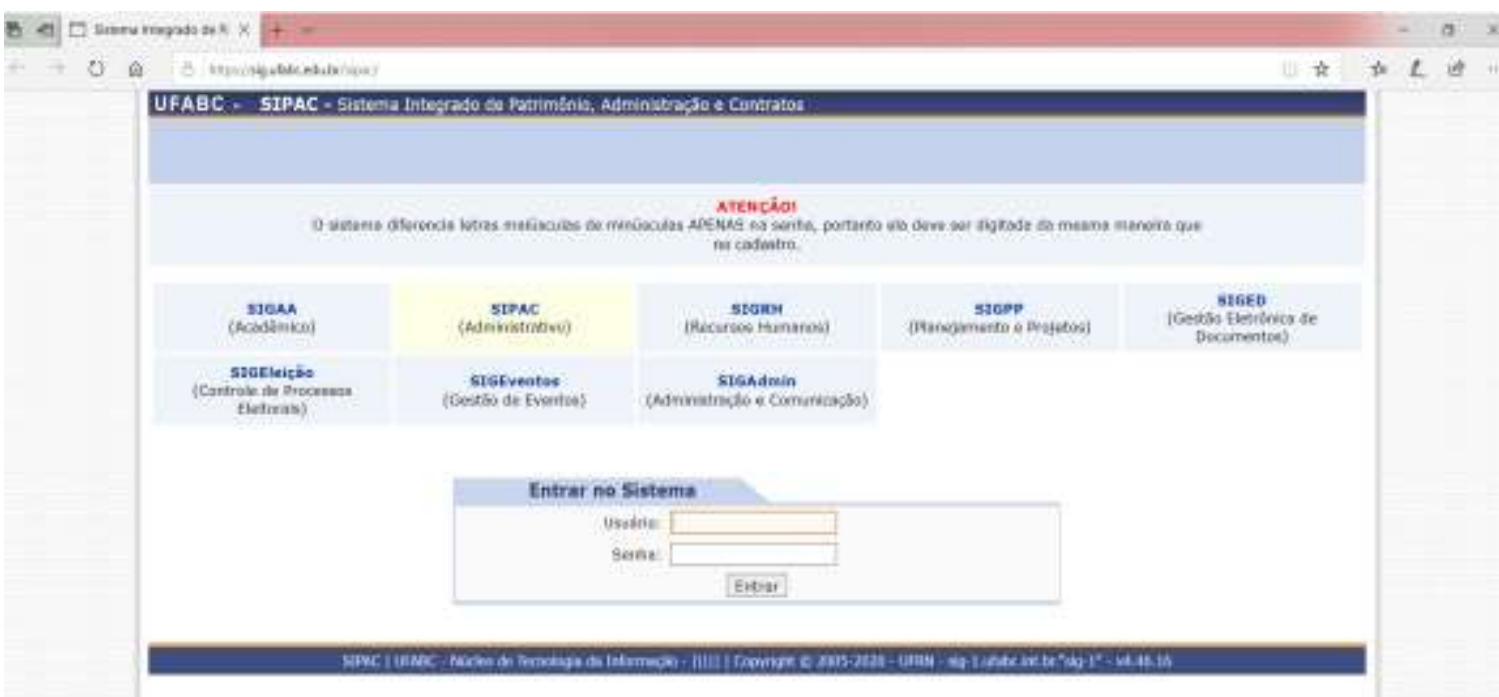

Fonte: SIPAC-UFABC (2020)

O processo é encaminhado à Pró-Reitoria de Planejamento e Desenvolvimento Institucional para a reserva de recursos orçamentários, sendo que a etapa seguinte é realizada pela ProAd por meio da Coordenação Geral de Finanças e Contabilidade (CGFC) que, por sua vez, realiza o pré-empenho, quando for o caso. Na sequência, o processo de compras é encaminhado à Divisão de Aquisições e Contratações (DAC) da ProAd para análise dos documentos juntados ao processo.

A análise criteriosa é realizada por um servidor lotado na DAC, o qual verifica se os documentos necessários constam no processo, bem como as alterações realizadas pela área técnica demandante, em especial se foram incluídos critérios de sustentabilidade nos itens que se pretende adquirir. Caso não sejam encontrados, ou em razão de incongruências ou falhas, é enviado e-mail à área técnica demandante, solicitando as correções e inclusões necessárias. Após as adequações, o processo é encaminhado à Procuradoria Jurídica da UFABC, que analisa a legalidade dos documentos e procedimentos, bem como verifica se foram incluídos os critérios de sustentabilidade e as justificativas para sua adoção ou para sua não inclusão no item a ser adquirido ou contratado.

$\mathrm{O}$ processo é encaminhado à $\mathrm{DAC} / \mathrm{ProAd}$ para que sejam realizadas eventuais alterações sugeridas pela Procuradoria Jurídica e, em seguida, o edital de licitação é publicado no Diário Oficial da União para divulgação aos interessados em atender à licitação.

Após a adoção das estratégias de inclusão dos critérios de sustentabilidade, o processo de compras públicas da UFABC recebeu o acréscimo de duas etapas importantes de verificação. Uma delas foi inserida na fase de análise da DAC/ProAd e outra durante a análise da Procuradoria Jurídica; tais etapas destinam-se justamente à verificação da inclusão dos critérios de sustentabilidade ou da apresentação de justificativa para a sua não adoção. A figura a seguir esquematiza esse processo. 
Figura 5 - Processo de compras públicas da UFABC após a adoção das estratégias

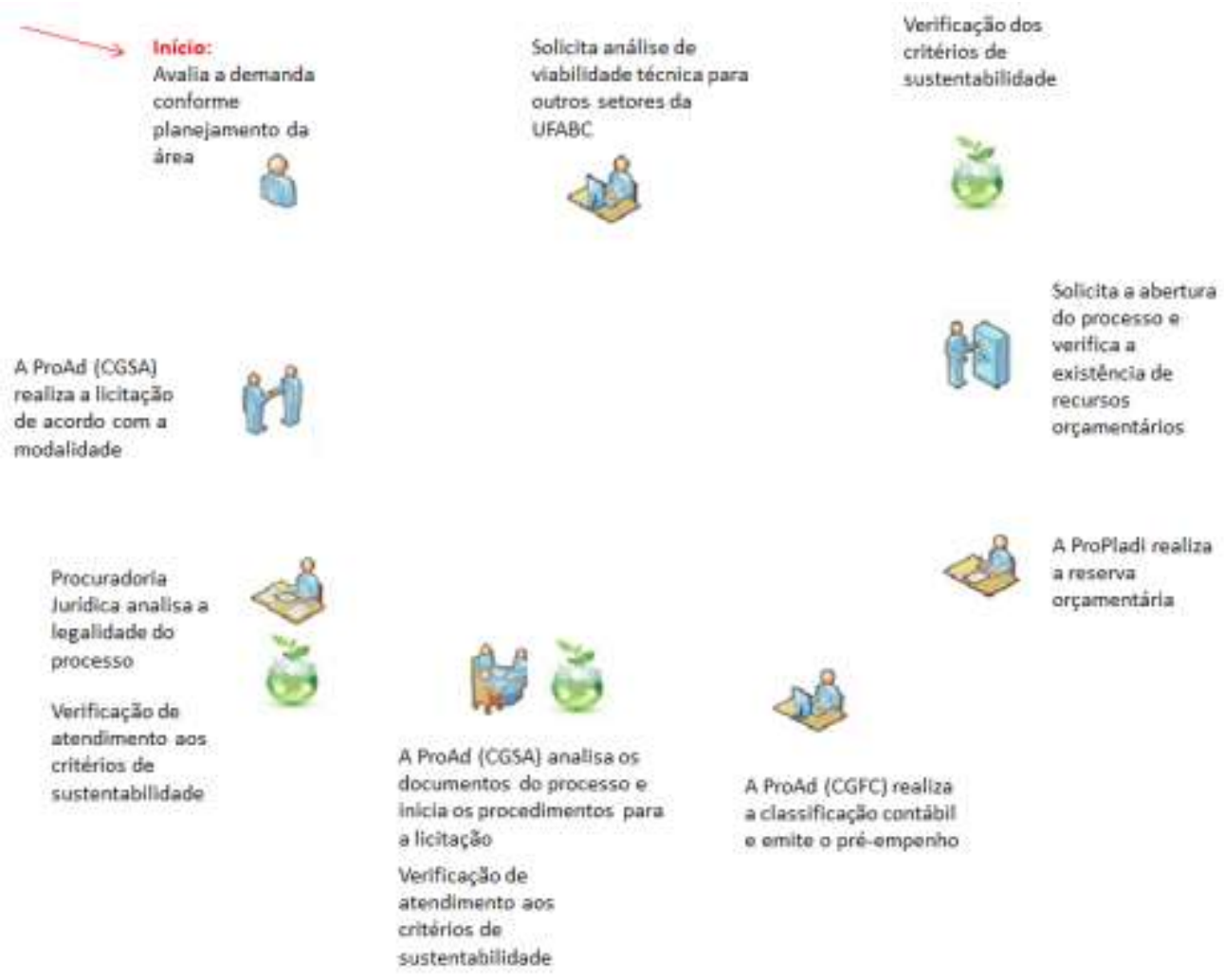

Fonte: Adaptado de ProAd - UFABC (2020).

A incorporação dos critérios de sustentabilidade nas compras e contratações da UFABC foi um processo que se desdobrou por meio da adoção de medidas como a realização de reuniões estratégicas e programas de capacitação de servidores, bem como pela instituição de comissões e grupos de trabalhos.

Dentre as metas efetivadas pela UFABC como resultado da implantação das estratégias para compras sustentáveis, destacam-se ações de compras compartilhadas entre os setores da universidade, a elaboração de documentos, como o Plano de Logística Sustentável, o estabelecimento de procedimentos internos, capacitação e conscientização frequentes dos servidores e o estabelecimento de etapas de verificação de critérios de sustentabilidade nos processos de compras.

Também benefícios indiretos foram colhidos pela UFABC como consequência da adoção de medidas visando uma atuação mais verde por parte da instituição como um todo, dentre eles, a redução dos gastos com energia elétrica nos campi, propiciada pela aquisição de lâmpadas de LED com selo PROCEL. E ainda no tocante às referidas medidas, destacam-se também a contratação de gráfica que fornece a impressão em papel reciclável e, mais recentemente, a entrada em vigência de cláusula contratual que exige da empresa responsável pela administração dos restaurantes universitários a aquisição de produtos alimentícios oriundos da agricultura familiar. A aquisição de produtos alimentícios do pequeno agricultor vai ao encontro das recomendações dos estudos de Neto (2020), que analisou os critérios para as compras públicas de alimentos. 
As estratégias adotadas na implementação de critérios de sustentabilidade no processo de suas compras públicas, por uma universidade federal com o cumprimento da legislação federal brasileira para compras sustentáveis, reforça a visão de Betiol (2013) que afirma que o Brasil possui normas rígidas para licitações sustentáveis.

No âmbito da UFABC, o principal desafio encontrado no processo de incorporação dos critérios de sustentabilidade às compras públicas foi o de internalizar e exteriorizar o conceito de sustentabilidade no cotidiano da comunidade acadêmica. Isso porque foram encontradas algumas limitações em entender e em divulgar as iniciativas na universidade, corroborando os achados das pesquisas de Delmonico et al. (2018) e de Jiménez et al. (2019), as quais assinalam, dentre suas conclusões, que a cultura organizacional pode ser uma barreira à contratação pública sustentável.

Os principais riscos estão relacionados à liberação de recursos orçamentários para as aquisições, baixa oferta de itens sustentáveis pelos fornecedores e a cultura prevalente de que produtos sustentáveis são mais caros (UFABC, 2015).

Por outro lado, as compras sustentáveis são uma forma de incentivar as empresas, em especial as micro e pequenas, a fornecer produtos e serviços com forte potencial de redução do impacto ambiental, conforme preconiza o estudo de Shi, Xue e Wang (2019).

A centralização das compras em um setor da universidade vai ao encontro do que estabelece o estudo de Glas et al. (2017), propiciando uma maior especialização nos processos e procedimentos internos, com a consequente conscientização dos servidores públicos e capacitação profissional para o bom desempenho de suas funções, em especial dos pregoeiros e dos membros da Comissão Permanente de Licitação (CPL).

\section{Conclusão}

A UFABC adotou diversas estratégias e intervenções para a implementação dos critérios de sustentabilidade nas compras públicas realizadas em seus campi.

Os principais resultados e metas efetivadas referem-se à elaboração de documentos internos, com atualizações frequentes em conformidade com a legislação; a conscientização dos servidores públicos da instituição quanto aos critérios de sustentabilidade nas compras públicas; a criação de um fluxo para as compras públicas pela UFABC, segundo o qual foi possível instruir os processos de compra com a inclusão de critérios de sustentabilidade em conformidade com as exigências legais.

A partir do estudo realizado, pode-se afirmar que a UFABC se encontra num estágio avançado rumo à efetivação e execução de uma política de compras sustentáveis. E como evidência disso, assinalam-se fatores como o estabelecimento de um fluxo contínuo de compras sustentáveis com etapas de verificação de atendimento aos critérios de sustentabilidade, a instituição de instrumentos como a Comissão Permanente de Licitações (CPL) e a Comissão Consultiva à Sustentabilidade (CCS), bem como a elaboração e constante acompanhamento da execução do Plano de Logística Sustentável. 
Nesse contexto, é pertinente uma avaliação, por parte dos governantes brasileiros, acerca da possibilidade de implantar um processo de compras sustentáveis, por intermédio de novas medidas regulatórias que aumentem a efetividade, eficácia e eficiência do referido processo. Contudo, será imprescindível levar em consideração o perfil e a natureza das atividades da organização, a fim de que as contratações e aquisições possam equacionar as boas práticas e atingir o bem-estar público. Além isso, também será necessário fornecer ferramentas de mensuração para facilitar a avaliação, abrindo espaço à elaboração de políticas públicas ambientais sustentáveis, e permitindo, assim, um emprego mais adequado das práticas e experiências.

O trabalho contribui para reforçar a importância da participação da comunidade universitária nas ações que visam a sustentabilidade, com a internalização e exteriorização dos conceitos sustentáveis nas atividades diárias, tanto acadêmicas, administrativas, quanto pessoais.

Por fim, o presente relato técnico visa contribuir para que outras instituições possam conhecer e adotar estratégias semelhantes em seus processos de estabelecimento de compras públicas sustentáveis. Além disso, o relato permite ampliar a discussão a respeito da relevância e aplicabilidade dos processos efetuados e resultados obtidos no âmbito da UFABC, dentre eles: a participação da comunidade universitária, a divulgação das informações, o monitoramento e a transparência das ações implementadas, o treinamento dos servidores e a conscientização das pessoas em relação às ações governamentais em prol de políticas que promovam um desenvolvimento mais sustentável do país.

\section{Referências}

Araújo, G. C. \& Teixeira, C. E. (2018). Análise das compras públicas sustentáveis na secretaria do meio ambiente do estado de São Paulo. Gestão \& Regionalidade, 34(100).

Bernal, Ramon; San-Jose, Leire; Retolaza, Jose Luis. Improvement Actions for a More Social and Sustainable Public Procurement: A Delphi Analysis. Sustainability, v. 11, n. 15, p. 4069, 2019.

Betiol, L.S. (2013), Contratações públicas como indutoras de sustentabilidade: a perspectiva do consumo sustentável. Avanços e desafios no cenário jurídico brasileiro, Tese de Doutorado, Programa de Estudos Pós-Graduados em Direito, Pontifícia Universidade Católica de São Paulo, São Paulo.

Brammer, S. \& Walker, H. (2011). Sustainable procurement in the public sector: an international comparative study. International Journal of Operations \& Production Management, 31(4), 452476.

Brasil, Brasília. Advocacia-Geral da União (AGU). Consultoria-Geral da União. Guia Nacional de Licitações Sustentáveis. Flávia Gualtieri de Carvalho, Maria Augusta Soares de Oliveira Ferreira e Teresa Villac, Brasília: AGU, p. 42, 2016.

Brasil, Brasília. Advocacia-Geral da União (AGU). Disponível em: https://www.agu.gov.br/unidade/MODELOSLICITACOES. Acesso em 23 de março de 2020.

Brasil. Decreto $n^{\circ}$ 7.746, de 5 de junho de 2012. Diário Oficial da União. Poder Executivo. Brasília, DF, Seção 107, nº, p. 9. 
Brasil. Lei $n^{\circ}$ 13.110, de 25 de março de 2015. Diário Oficial da União. Poder Executivo. Brasília, DF, Seção $1, \mathrm{n}^{\circ} 58$, p. 2.

Chersan, I. C., Dumitru, V. F., Gorgan, C. \& Gorgan, V. (2020). Green Public Procurement in the Academic Literature. The AMFITEATRU ECONOMIC journal, 22(53), 1-82.

Chiarini, A., Opoku, A. \& Vagnoni, E. (2017). Public healthcare practices and criteria for a sustainable procurement: A comparative study between UK and Italy. Journal of Cleaner Production, 162, 391-399.

Claro, E., Emhart, C., Kneppers, B. \& Sinclair, S. 2013. Seizing Ecolabelling and Sus- tainable Public Procurement Opportunities in the Southern Cone Region. Nordic Working Papers 2013:919. Nordic Council of Ministers, Copenhagen.

Delmonico, D., Jabbour, C. J. C., Pereira, S. C. F., Sousa Jabbour, A. B. L. de, Renwick, D. W. S. \& Thomé, A. M. T. (2018). Unveiling barriers to sustainable public procurement in emerging economies: Evidence from a leading sustainable supply chain initiative in Latin America. Resources, Conservation and Recycling, 134, 70-79.

ENAP (2020). Escola Nacional de Administração Pública. Disponível em: https://www.enap.gov.br/pt/. Acesso em: 22 de março de 2020.

Erridge, A. \& Mcllroy, J. (2002). Public procurement and supply management strategies. Public policy and administration, 17(1), 52-71.

Eriksson, P. E. \& Westerberg, M. (2011). Effects of cooperative procurement procedures on construction project performance: A conceptual framework. International journal of project management, 29(2), 197-208.

Faganello, C. R. F., Santos, Á. R. A. \& Fonseca Filho, L. F. (2015). Compras Públicas Sustentáveis na Universidade Federal do Recôncavo da Bahia. Campo Jurídico, 3(1), 15-51.

Gelderman, C. J., Semeijn, J. \& Bouma, F. (2015). Implementing Sustainability in Public Procurement: The Limited Role of Procurement Managers and Party-Political Executives. Journal of Public Procurement, 15 (1): 66-92.

Glas, A. H., Schaupp, M. \& Essig, M. (2017). An organizational perspective on the implementation of strategic goals in public procurement. Journal of Public Procurement, 17(4).

Jimenez, J. M., Lopez, M. H. \& Escobar, S. E. F. (2019). Sustainable Public Procurement: From Law to Practice. Sustainability, 11(22), 6388.

Liu, J., Shi, B., Xue, J. \& Wang, Q. (2019). Improving the green public procurement performance of Chinese local governments: From the perspective of officials' knowledge. Journal of Purchasing and Supply Management, 25(3), 100501.

Mattar, F. N. Pesquisa de marketing. 3. ed. São Paulo: Atlas, 2001. 275 p.

McMurray, A. J., Islam, M. M., Siwar, C. \& Fien, J. (2014). Sustainable procurement in Malaysian organizations: Practices, barriers and opportunities. Journal of Purchasing and Supply Management, 20(3), 195-207.

Melissen, F. \& Reinders, H. (2012). A reflection on the Dutch sustainable public procurement programme. Journal of Integrative Environmental Sciences, 9(1), 27-36. 
Neto, B. (2020). Analysis of sustainability criteria from European public procurement schemes for foodservices. Science of The Total Environment, 704, 135300.

Oliveira, B. C. S. \& Santos, L. M. L. (2015). Compras públicas como política para o desenvolvimento sustentável. Revista de Administração Pública, 49(1), 189-206.

Oliveira, M. M. de. Como fazer pesquisa qualitativa. 2 ed. Petrópolis, RJ: Vozes, 2008.

Oruezabala, G. \& Rico, J. C. (2012). The impact of sustainable public procurement on supplier management-The case of French public hospitals. Industrial Marketing Management, 41(4), 573580.

Paterson, Barbara L.; Bottorff, Joan L. \& Hewat, Roberta. Blending observational methods: Possibilities, strategies, and challenges. International Journal of Qualitative Methods, v. 2, n. 1, p. 29-38, 2003.

Rainville, A. (2017). Standards in green public procurement-A framework to enhance innovation. Journal of Cleaner Production, 167, 1029-1037.

Silva, R. C., Betiol, L., Villac, T. \& Nonato, R. (2018). Sustainable public procurement: The Federal Public Institution's shared system. Revista de Gestão.

Sousa Jabbour, A. B. L., Jabbour, C. J. C., Sarkis, J. \& Govindan, K. (2014). Brazil's new national policy on solid waste: challenges and opportunities. Clean Technologies and Environmental Policy, 16(1), 7-9.

Sönnichsen, S. D. \& Clement, J. (2019). Review of green and sustainable public procurement: Towards circular public procurement. Journal of Cleaner Production, 118901.

UFABC (2015). Plano de Logística Sustentável: PLS 2015-2022. São Bernardo do Campo - SP: Editora da Universidade Federal do ABC, 2015. Disponível em: http://propladi.ufabc.edu.br/images/pls/livro_pls.pdf. Acesso em: 21 março de 2020.

UFABC (2020). Pró-Reitoria de Administração. Disponível em: http://proad.ufabc.edu.br/. Acesso em: 03 de abril de 2020.

UNEP, Global Review of Sustainable Public Procurement (2017). Disponível em: https://www.unenvironment.org/resources/report/2017-global-review-sustainable-publicprocurement. Acesso em: 03 de abril de 2020.

Uttam, K. \& Roos, C. L. L. (2015). Competitive dialogue procedure for sustainable public procurement. Journal of Cleaner Production, 86, 403-416.

Trindade, P. C., Antunes, P, \& Partidário, P. (2017). SPP toolbox: Supporting sustainable public procurement in the context of socio-technical transitions. Sustainability, 10(1), 1-26.

Walker, H. \& Brammer, S. (2012). The relationship between sustainable procurement and eprocurement in the public sector. International Journal of Production Economics, 140(1), 256-268.

Walker, H., Spencer, R., Miemczyk, J. \& Johnsen, T. (2010). “'Sustainable procurement'. Journal of Purchasing \& Supply Management, 16, 150.

Weingaertner, C. \& Moberg, Å. (2014). Exploring social sustainability: Learning from perspectives on urban development and companies and products. Sustainable Development, 22(2), 122-133.

Yin, R. K. (2015). Estudo de Caso: Planejamento e métodos. Bookman Editora. 